\title{
BIOMIMETIC SULPHATED ALGINATE HYDROGELS SUPPRESS IL-1B-INDUCED INFLAMMATORY RESPONSES IN HUMAN CHONDROCYTES
}

\author{
Ø. Arlov ${ }^{1,2, \S}$, E. Öztürk ${ }^{3,}$, M. Steinwachs ${ }^{4}$, G. Skjåk-Bræk ${ }^{1}$ and M. Zenobi-Wong ${ }^{3 *}$ \\ ${ }^{1}$ Department of Biotechnology, Norwegian University of Science and Technology, Sem Sælands vei 6/8, \\ 7034 Trondheim, Norway \\ ${ }^{2}$ Department of Biotechnology and Nanomedicine, SINTEF Materials and Chemistry, Richard Birkelands vei 3 B, \\ 7034 Trondheim, Norway \\ ${ }^{3}$ Cartilage Engineering \& Regeneration, ETH Zürich, Otto-Stern-Weg 7, 8093 Zürich, Switzerland \\ ${ }^{4}$ SportClinic Zürich, Hirslandenklinik, Witellikerstrasse 40, 8032 Zürich, Switzerland
}

$\S$ These authors contributed equally to this manuscript

\begin{abstract}
Loss of articular cartilage from ageing, injury or degenerative disease is commonly associated with inflammation, causing pain and accelerating degradation of the cartilage matrix. Sulphated glycosaminoglycans (GAGs) are involved in the regulation of immune responses in vivo, and analogous polysaccharides are currently being evaluated for tissue engineering matrices to form a biomimetic environment promoting tissue growth while suppressing inflammatory and catabolic activities. Here, we characterise physical properties of sulphated alginate (S-Alg) gels for use in cartilage engineering scaffolds, and study their anti-inflammatory effects on encapsulated chondrocytes stimulated with IL-1 $\beta$. Sulphation resulted in decreased storage modulus and increased swelling of alginate gels, whereas mixing highly sulphated alginate with unmodified alginate resulted in improved mechanical properties compared to gels from pure S-Alg. S-Alg gels showed extensive anti-inflammatory and anti-catabolic effects on encapsulated chondrocytes induced by IL-1 $\beta$. Cytokine-stimulated gene expression of pro-inflammatory markers IL-6, IL-8, COX-2 and aggrecanase ADAMTS-5 were significantly lower in the sulphated gels compared to unmodified alginate gels. Moreover, sulphation of the microenvironment suppressed the protein expression of COX -2 and NF- $\kappa$ B as well as the activation of NF- $\kappa B$ and p38-MAPK. The sulphated alginate matrices were found to interact with IL-1 $\beta$, and proposed to inhibit inflammatory induction by sequestering cytokines from their receptors. This study shows promising potential for sulphated alginates in biomimetic tissue engineering scaffolds, by reducing cytokine-mediated inflammation and providing a protective microenvironment for encapsulated cells.
\end{abstract}

Keywords: Alginate gels, sulphated alginate, cartilage regeneration, human chondrocytes, inflammation.

*Address for correspondence:

Marcy Zenobi-Wong

Cartilage Engineering \& Regeneration

ETH Zürich

Otto-Stern-Weg 7, 8093 Zürich, Switzerland

Telephone: +41446325089

e-mail: marcy.zenobi@hest.ethz.ch

\section{Introduction}

Osteoarthritis $(\mathrm{OA})$ can be idiopathic in nature or initiated by trauma, joint malformation or excessive load on joints (Clutterbuck et al., 2009). Recent evidence has shown that OA also has an inflammatory component (Berenbaum, 2013; Konttinen et al., 2012), where matrix fragments can signal through toll-like receptors. Proteolytic degradation of the matrix can also release immobilised cytokines such as interleukin (IL)-1 $\beta$ and IL- 6 and tumour necrosis factor (TNF) which in turn further induce cytokine expression and secretion of matrix-degrading enzymes from chondrocytes, thus propagating tissue breakdown (David et al., 2007; Martel-Pelletier, 1999). These effects are largely mediated by nuclear transcription factors such as nuclear factor-kappaB (NF-kB), which has been shown to induce expression of inflammatory cytokines, matrix metalloproteinases (MMPs), cyclooxygenase-2 (COX2 ), as well as adhesion molecules (ICAM-1, VCAM-1 and E-selectin) implicating NF- $\mathrm{BB}$ in the recruitment of leukocytes (Ke et al., 2007; Miagkov et al., 1998).

Cultivation of chondrocytes in vitro is a strategy of cell-based therapies to repair damaged and diminished cartilage due to injuries or degenerative diseases. One approach is by autologous chondrocyte implantation (ACI), where chondrocytes are isolated from a biopsy of healthy cartilage and passaged in vitro, followed by reintroduction to the defect site (Risbud and Sittinger, 2002). Matrixinduced autologous chondrocyte implantation (MACI) has been developed as a technique to incorporate a supportive scaffold for the chondrocytes to enhance cartilage matrix synthesis, overcome donor variability and improve the clinical outcome (Makris et al., 2015). Scaffolds for cartilage regeneration must provide a suitable environment with physical support and hydration, promote proliferation and production of extracellular matrix and prevent dedifferentiation of the chondrocytes (Darling and Athanasiou, 2005; Holtzer et al., 1960). The engineered biological or synthetic matrix must be biocompatible and have low immunogenicity to prevent an inflammatory response in the host upon introduction of cultivated tissues. Furthermore, it should serve as a protective microenvironment for the encapsulated cells against the effects from the inflamed defect site such as diffusion of inflammatory cytokines or matrix-degrading enzymes. Therefore, developing biomimetic materials with both intrinsic anti-inflammatory and chondropermissive 
properties is crucial for improving the clinical success of tissue engineering strategies in cartilage repair.

Articular cartilage is rich in sulphated glycosaminoglycans (GAGs) which have significant roles in hydration, cell motility and intra- and intercellular communication, and are thus of great interest for incorporation in tissue engineering scaffolds (Chen et al., 2007; Pieper et al., 2000). Heparin, in particular, has been shown to have anti-inflammatory effects by reducing nuclear translocation of $\mathrm{NF}-\kappa \mathrm{B}$, thus lowering expression of inflammatory cytokines, and may further inhibit downstream processes by direct association with cytokines, adhesion proteins and the complement and coagulation cascades (Hochart et al., 2006; Parish, 2006; Spillmann et al., 1998; Weiler et al., 1992).

Alginate has long been considered for cell encapsulation due its gentle gelling conditions, good biocompatibility and high availability (Rehm and Valla, 1997). As native alginate is relatively inert, functionalisation by covalent modification has been extensively explored (Dalheim et al., 2015; Pawar and Edgar, 2012; Rowley et al., 1999). One such strategy is by chemical sulphation, increasing the negative charge and thus promoting electrostatic interactions characteristic of sulphated GAGs. We have previously presented sulphated alginate as a potential heparin/heparan sulphate analogue, as it associates with heparin-binding proteins and exhibits anti-inflammatory effects in blood (Arlov et al., 2015; Arlov et al., 2014; Arlov et al., 2016). Furthermore, we recently demonstrated that sulphated alginate gels induce mitogenicity of chondrocytes within a three-dimensional microenvironment while preserving their native phenotype, by mediating fibroblast growth factor (FGF) signalling (Öztürk et al., 2016). As cells have specific requirements to their surrounding scaffold, a sulphated alginate-based matrix may show promise in its customisability, through sequence modifications using C5-epimerases (Ertesvåg, 2015) and by tuning the sulphation degree (DS) to optimise biological efficacy while minimising cross-reactivity and destabilisation of the matrix.

Compared to unmodified alginate, sulphated alginates form weaker gels which swell and disrupt faster as a function of sulphation degree, due to the relatively bulky sulphate groups preventing ideal network formation described in the "egg-box" model (Grant et al., 1973). It is therefore desirable to evaluate whether pure sulphated alginate gels are necessary for the observed beneficial effects, and if gel stability can be increased by mixing with unmodified alginate without loss of effectiveness.

In the present work, we explored the effect of sulphation on the physical properties of alginate gels, as well as the chondropermissive and immunoprotective effects on human chondrocytes. To study the anti-inflammatory potential and the influence of sulphate content, human chondrocytes were encapsulated in hydrogels containing varying amounts of sulphated alginate, and the expression of inflammatory and catabolic markers was studied following stimulation with IL-1 $\beta$.

\section{Materials and methods}

\section{Sulphation of alginates}

The alginate used was protanal LF200S $\left(\mathrm{F}_{\mathrm{G}}=0.68, \mathrm{M}_{\mathrm{w}}\right.$ $=270 \mathrm{kDa},[\eta]=1085 \mathrm{dL} / \mathrm{g}$ ), referred throughout as Alg, extracted from the stipe of Laminaria hyperborea (FMC Biopolymer). Sulphation of the alginate was performed using $99 \%$ chlorosulphonic acid (Sigma) in formamide (Merck) as previously described(Arlov et al., 2014), with an $\mathrm{HClSO}_{3}$ concentration range of $1.5-4.0 \mathrm{vol} \%$ in formamide at $60^{\circ} \mathrm{C}$ for $2.5 \mathrm{~h}$. High Resolution Inductively Coupled Plasma Mass Spectrometry (HR-ICP-MS) was employed to quantify the $\mathrm{wt} \%$ content of sulphur in the lyophilised samples, and the average number of sulphates per monosaccharide (DS) was estimated, using the following equation (MM, monosaccharide mass):

$$
\mathrm{MM}=\mathrm{C}_{6} \mathrm{O}_{6} \mathrm{H}_{5}+(\mathrm{DS}+1) \mathrm{Na}^{+}+\left(\mathrm{DS} \times \mathrm{SO}_{3}^{-}\right)+\mathrm{H}_{2} \mathrm{O}
$$

The sulphated alginates (S-Alg) were analysed by NMR, showing a sulphation pattern consistent with previous findings (not shown). For further structural characterisation of sulphated alginates, the reader is referred to earlier publications (Arlov et al., 2015; Arlov et al., 2014). The molecular weight of the alginates was measured using size exclusion chromatography with light scattering (SECMALS).

\section{Rheological characterisation of sulphated alginate gels}

Alg and S-Alg were dissolved in deionised water and mixed with calcium carbonate $\left(\mathrm{CaCO}_{3}\right)$ before degassing using a vacuum pump to remove air bubbles. Glucono- $\delta$ lactone (GDL) (Sigma) was dissolved in deionised water and added to the alginate solution under gentle stirring. Final concentrations of $\mathrm{CaCO}_{3}$ and GDL were respectively $30 \mathrm{mM}$ and $60 \mathrm{mM}$ for a $2 \mathrm{wt} / \mathrm{vol} \% \mathrm{Alg} / \mathrm{S}-\mathrm{Alg}$ solution. The mixture $(2 \mathrm{~mL})$ was immediately applied to a Kinexus rheometer system (Malvern, Worcestershire, UK) equipped with $40 \mathrm{~mm}$ serrated geometry, and the storage modulus of the gelling solution was measured at $20^{\circ} \mathrm{C}$ over $15 \mathrm{~h}$ in oscillatory mode at $1 \mathrm{~Hz}$ and 0.005 strain, with a solvent trap to reduce evaporation. The data were recorded and processed using the software rSpace (Malvern).

\section{Swelling properties of sulphated alginate gels}

Solutions were prepared from Alg or Alg mixed with $20-80 \mathrm{wt} \% \mathrm{~S}-\mathrm{Alg}(\mathrm{DS}=0.90)(2 \mathrm{wt} / \mathrm{vol} \%$ in $300 \mathrm{mM}$ mannitol), and their average diameter was measured following hourly changes of the saline. Alginate/sulphated alginate gel beads were prepared using a Pasteur pipette to drip the polysaccharide solution into a gelling bath of $50 \mathrm{mM}$ calcium chloride $\left(\mathrm{CaCl}_{2}\right)$ or $50 \mathrm{mM} \mathrm{CaCl}_{2}+1 \mathrm{mM}$ barium chloride $\left(\mathrm{BaCl}_{2}\right)$, both supplemented with $150 \mathrm{mM}$ mannitol. Mannitol was added to the alginate solution and gelling bath as an osmolyte that does not interact with cross-linking junction zones in alginate. The gels were left overnight in the gelling solution before transferring them to $150 \mathrm{mM}$ sodium chloride $(\mathrm{NaCl})$. The average diameter of the gels was then measured following hourly replacements 
of a $150 \mathrm{mM} \mathrm{NaCl}$ medium. The sulphur, barium and calcium concentrations of the gels were measured at three time points at the start, middle and end of the experiment, by dissolving 20 gels in ethylenediaminetetraacetic acid (EDTA) at $18 \mathrm{mM}$ for calcium gels or $36 \mathrm{mM}$ for calciumbarium gels, followed by elemental analysis using HRICP-MS.

\section{Chondrocyte isolation}

Human chondrocytes were isolated from non-arthritic articular cartilage obtained from surgical knee operations (over 60 years old, male) (ethics approval number KEKZH 2013-0097) and kept in phosphate-buffered saline (PBS) supplemented with $10 \mu \mathrm{g} / \mathrm{mL}$ gentamycin (Gibco). The cartilage specimens were minced into 1-3 $\mathrm{mm}^{3}$ pieces with a sterile blade and washed with Dulbecco's modified eagle medium (DMEM) (Glutamax, high glucose) (Invitrogen) with $10 \mu \mathrm{g} / \mathrm{mL}$ gentamycin. Minced cartilage tissue was digested with $0.1 \%$ collagenase (Sigma) in DMEM supplemented with $10 \%$ foetal bovine serum (FBS) (Invitrogen) overnight at $30^{\circ} \mathrm{C}$ with gentle shaking. Digested tissue was filtered through a $100 \mu \mathrm{m}$ and then a $40 \mu \mathrm{m}$ cell strainer. The filtered solution of chondrocytes was centrifuged at $500 \times \mathrm{g}$ for $10 \mathrm{~min}$ and washed twice with growth medium (DMEM containing $10 \% \mathrm{FBS}, 50 \mu \mathrm{g} /$ $\mathrm{mL} L$-ascorbic acid -2-phosphate (Sigma) and $10 \mu \mathrm{g} / \mathrm{mL}$ gentamycin). The chondrocytes were seeded at a density of 3000 cells $/ \mathrm{cm}^{2}$ and expanded in growth medium to passage 4 before encapsulation in the hydrogels.

\section{Chondrocyte encapsulation in hydrogels}

Gel precursor solutions of Alg, S-Alg (DS = 0.32) and mixtures of Alg/S-Alg (20, 40 or $60 \mathrm{wt} \%$ of S-Alg $(\mathrm{DS}=0.9)$ ) were prepared in $150 \mathrm{mM} \mathrm{NaCl}$ and sterile filtered $(0.2 \mu \mathrm{m}$ pore size $)$. The solutions were gently mixed with a concentrated cell suspension to yield $2 \mathrm{wt} /$ vol $\%$ polymer solution with a cell density of $6 \times 10^{6}$ cells/ $\mathrm{mL} .30 \mu \mathrm{L}$ discs of each solution were cast and gelled in $100 \mathrm{mM} \mathrm{CaCl}_{2}$ for $20 \mathrm{~min}$. Chondrocytes encapsulated in hydrogels were cultured in growth medium supplemented with $3 \mathrm{mM} \mathrm{CaCl}_{2}$.

\section{Assessment of cell viability and morphology}

In order to assure the cells were viable before addition of IL-1 $\beta$, viability and morphology were assessed. After 1 week of culture, the gels were incubated in growth medium supplemented with $2 \mu \mathrm{M}$ calcein AM and $20 \mu \mathrm{M}$ propidium iodide for $1 \mathrm{~h}$ at $37^{\circ} \mathrm{C}$. The gels were washed twice with growth medium for 20 min and imaged with fluorescence microscopy (Zeiss Axio Observer). For assessment of cell morphology, the gels were fixed with $4 \%$ formaldehyde (Sigma) with $0.1 \%$ Triton-X-100 (Sigma) in PBS for $1 \mathrm{~h}$ at $4{ }^{\circ} \mathrm{C}$ and washed twice with $150 \mathrm{mM} \mathrm{NaCl}$ and $5 \mathrm{mM} \mathrm{CaCl}_{2}$. Then the gels were stained with phalloidin-rhodamine for actin and 4',6-diamidino-2phenylindole (DAPI) for DNA for 45 min followed by two washes with $150 \mathrm{mM} \mathrm{NaCl}$ and $5 \mathrm{mM} \mathrm{CaCl}_{2}$ and imaged with fluorescence microscopy. For the quantification of viability, $200 \mu \mathrm{M}$ z-stacks from the gels were projected with maximum intensity followed by determination of the number of live and dead cells with ImageJ. Twenty images from each sample were projected for analysis and three replicates were used for each condition.

\section{Chondrogenic redifferentiation and immunohistochemistry}

For the assessment of chondrogenic redifferentiation, chondrocytes were encapsulated in the hydrogels $(n=3$ for all conditions) and cultured for 3 weeks in chondrogenic medium (DMEM supplemented with $1 \%$ ITS+ Premix (Corning), $50 \mu \mathrm{g} / \mathrm{ml} \mathrm{L}$-ascorbic acid -2-phosphate, $10 \mu \mathrm{g} / \mathrm{mL}$ gentamycin, $40 \mu \mathrm{g} / \mathrm{mL}$ L-proline, $100 \mathrm{nM}$ dexamethasone and $10 \mathrm{ng} / \mathrm{mL}$ transforming growth factor- $\beta 3$ (TGF- $\beta 3$ ) (Peprotech)). After 3 weeks, the gels were collected and fixed with $4 \%$ formaldehyde with $0.1 \%$ Triton-X in PBS for $1 \mathrm{~h}$ at $4{ }^{\circ} \mathrm{C}$. Then, the gels were washed twice with $150 \mathrm{mM} \mathrm{NaCl}$ supplemented with $5 \mathrm{mM}$ $\mathrm{CaCl}_{2}$. The hydrogels were incubated with a 1:1 mixture of PBS and optimum cutting temperature compound (OCT) (VWR) for $2 \mathrm{~h}$ at RT and then were completely embedded in OCT overnight. The gels were snap-frozen on dry ice and cut with a cryotome (CryoStar NX70, ThermoScientific) in $5 \mu \mathrm{m}$ sections. The sections were fixed with $96 \%$ ethanol and washed several times with PBS to remove the OCT. Epitope retrieval was performed by incubating the sections in $2 \mathrm{mg} / \mathrm{mL}$ hyaluronidase (Sigma) in PBS for $30 \mathrm{~min}$ at $37^{\circ} \mathrm{C}$. Then, the sections were blocked for $1 \mathrm{~h}$ at RT with $5 \%$ bovine serum albumin (BSA) followed by incubation with the primary antibody in $1 \% \mathrm{BSA}$ at $4{ }^{\circ} \mathrm{C}$ overnight. The sections were washed three times in PBS and incubated with the secondary antibody in $1 \%$ BSA (IgG goat antimouse AlexaFluor488, Invitrogen) for $1 \mathrm{~h}$ at RT. The samples were washed with PBS, stained with DAPI for 15 min, washed again, mounted with aqueous mounting media (Vector Laboratories) and imaged with fluorescence microscopy. The primary antibodies used were mouse anticollagen II (II-II6B3, Developmental Studies Hybridoma Bank) and mouse anti-collagen I (Abcam).

\section{Inflammatory induction of chondrocytes with IL-1及}

The hydrogels were cultured for a week in growth medium and serum starved overnight before the inflammatory induction. Then, the hydrogels were cultured with medium containing DMEM supplemented with $50 \mu \mathrm{g} / \mathrm{mL}$ L-ascorbic acid-2-phosphate, $10 \mu \mathrm{g} / \mathrm{mL}$ gentamycin and $1 \mathrm{ng} / \mathrm{mL}$ IL-1 $\beta$ (Peprotech) for either $24 \mathrm{~h}$ or $48 \mathrm{~h}$ before harvesting of the samples.

\section{Western blotting}

After 24 or $48 \mathrm{~h}$ of IL-1 $\beta$ induction hydrogels $(\mathrm{n}=3$ for all conditions) were washed twice with $150 \mathrm{mM}$ $\mathrm{NaCl}$ and $5 \mathrm{mM} \mathrm{CaCl}$ and stored at $-80{ }^{\circ} \mathrm{C}$. The frozen hydrogels were homogenised with a pestle in radioimmunoprecipitation assay (RIPA) buffer with protease inhibitors (Sigma), incubated on ice for $1 \mathrm{~h}$, and then centrifuged at $10,000 \times g$ for $15 \mathrm{~min}$. The supernatant was collected and the protein concentration was determined by Bradford assay (Bio-Rad). Samples were adjusted to $0.5 \mu \mathrm{g} / \mu \mathrm{L}$ concentration with RIPA and Laemmli buffer and denatured at $95^{\circ} \mathrm{C}$ for $5 \mathrm{~min} .10 \mu \mathrm{g}$ protein was loaded in pre-cast $4-12 \%$ Bis-Tris gels (Invitrogen) and run for $35 \mathrm{~min}$ at $125 \mathrm{~V}$ followed by transfer onto a nitrocellulose 
membrane for $1 \mathrm{~h}$ at $25 \mathrm{~V}$. The membrane was washed twice with $\mathrm{ddH}_{2} \mathrm{O}$, stained with Ponceau S (Sigma) for protein visualisation and washed three times with tris-buffered saline with tween-20 (TBST) buffer. The membrane was then blocked with $5 \%$ BSA for $1 \mathrm{~h}$ at RT and incubated with primary antibody overnight at $4{ }^{\circ} \mathrm{C}$. The membrane was washed four times with TBST and then incubated with the secondary antibody for $1 \mathrm{~h}\left(25^{\circ} \mathrm{C}\right)$, washed again and visualised with Clarity Western ECL Substrate (Bio-Rad) for chemiluminescence. The primary antibodies used were anti-COX-2, anti-phospho-NF- $\mathrm{B}$ p65 (Ser 536), antiNF-кB p65, anti-phospho-p38-MAPK (Thr180/Tyr182) (Cell Signaling Technology) and anti-actin (Sigma). The secondary antibody was anti-rabbit-HRP (Cell Signaling Technology).

\section{Real-time PCR}

Samples were collected ( $n=3$ for all conditions) and frozen at $-80^{\circ} \mathrm{C}$ until used. The hydrogels were homogenised with a tissue pestle in Trizol $^{\circledR}$ (Invitrogen), and centrifuged at $12,000 \times g$ for $10 \mathrm{~min}$ at $4^{\circ} \mathrm{C}$. The supernatant was removed and chloroform was added followed by centrifugation at $12,000 \times g$ for $15 \mathrm{~min}$ at $4{ }^{\circ} \mathrm{C}$, before removing the aqueous phase. RNA isolation was performed using the NucleoSpin miRNA kit (Macherey-Nagel AG) according to the manufacturer's instructions. Quantification of RNA concentration was done with a plate reader (Tek3 plate,
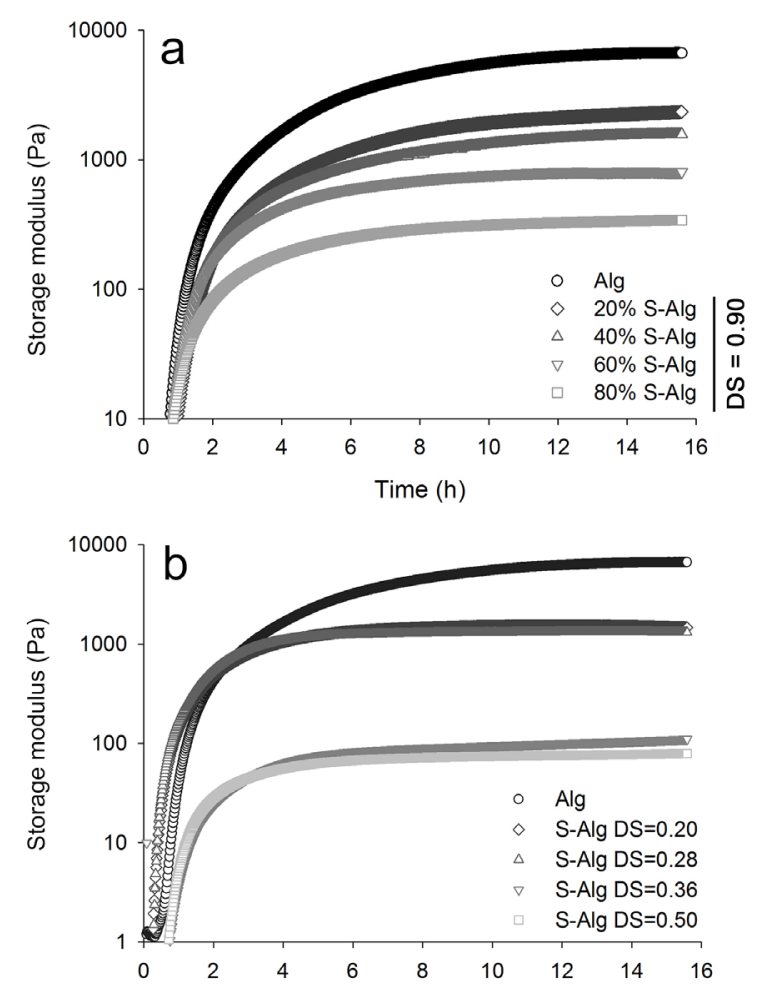

Fig. 1. Measurement of the storage modulus in solutions of (a) alginate (Alg) mixed with sulphated alginate (S$\mathrm{Alg}, \mathrm{DS}=0.90)$, or (b) exclusively sulphated alginate with increasing sulphation degree during gelation (15 h). Solutions were gelled with $30 \mathrm{mM} \mathrm{CaCO}_{3}$ and $60 \mathrm{mM}$ GDL for a final polysaccharide concentration of $2 \% \mathrm{w} / \mathrm{v}$. Oscillating shear deformation was carried out at $20{ }^{\circ} \mathrm{C}$ with a frequency of $1 \mathrm{~Hz}$ and strain of 0.005 .
Synergy, BioTek, Inc.). RNA was reverse transcribed using SuperScript III reverse transcriptase (Invitrogen) and the resulting cDNA was amplified by quantitative real-time PCR (StepOnePlus, Applied Biosystems) with Fast $\mathrm{SYBR}^{\circledR}$ Green master mix (Invitrogen). Ribosomal protein L13 (RPL13a) was used as an internal reference gene and fold change was quantified with the $\Delta \Delta \mathrm{Ct}$ method. The following primers for human (Microsynth $\mathrm{AG}$ ) were used in this study: RPL13a (forward (F) 5'-AAGTACCAGGCAGTGACAG-3'; reverse (R) 5'-CCTGTTTCCGTAGCCTCATG-3'), COX-1 (forward (F) 5'-CTCTTCGTCTGATCCGTCCTA-3'; reverse (R) 5'-TGAGGTTGCGGTCTGTTAGT-3'), COX-2 (forward (F) 5'-GCAATAACGTGAAGGGCTGT-3'; reverse (R) 5'-CGGGAAGAACTTGCATTGAT-3'), IL-6 (forward (F) 5'-GAAAGCAGCAAAGAGGCACT-3'; reverse (R) 5'-TTTCACCAGGCAAGTCTCCT-3'), IL-8 (forward (F) 5'-GTTCCACTGTGCCTTGGTTT-3'; reverse (R) 5'-GCTTCCACATGTCCTCACAA-3'), $M M P-13$ (forward (F) 5'-TGGTCCAGGAGATGAAGACC-3'; reverse (R) 5'-TCCTCGGAGACTGGTAATGG-3'), ADAMTS-5 (forward (F) 5'-CGATGGCACTGAATGTAGGC-3'; reverse (R) 5'-CTCCGCACTTGTCATACTGC-3').

\section{Enzyme Linked Immunosorbent Assay (ELISA) for quantification of IL-1 $\beta$ retention}

Hydrogel precursor solutions were mixed with IL-1 $\beta$ (R\&D Systems) to yield a polymer concentration of $2 \mathrm{wt} / \mathrm{vol} \%$ and cytokine concentration of $1 \mathrm{ng} / 30 \mu \mathrm{L}$ and the mixtures were incubated at RT for 2 h. $30 \mu \mathrm{L}$ discs from each solution were pipetted onto casters and gelled in $102 \mathrm{mM} \mathrm{CaCl}_{2}$ for $20 \min$ ( $n=3$ for all conditions). Then, the hydrogels were incubated in a buffer containing $150 \mathrm{mM} \mathrm{NaCl}, 5 \mathrm{mM}$ $\mathrm{CaCl}_{2}$ and $1 \mathrm{mg} / \mathrm{mL}$ bovine serum albumin (BSA) (Sigma) for 24 or $48 \mathrm{~h}$. The gels were collected at given time points and dissolved by incubating in a buffer containing $55 \mathrm{mM}$ sodium citrate, $30 \mathrm{mM}$ EDTA and $150 \mathrm{mM} \mathrm{NaCl}$ at $\mathrm{pH} 6.8$ for $10 \mathrm{~min}$ with shaking at $1,000 \mathrm{rpm}$ at RT. IL$1 \beta$ retention in the hydrogels was quantified by an IL- $1 \beta$ enzyme-linked immunosorbent assay (ELISA) kit (R\&D Systems) according to manufacturer's instructions.

\section{Statistical analysis}

Quantitative data was expressed as mean \pm standard deviation (s.d.). Statistical analyses were performed with OriginPro 9.1 by analysis of variance (ANOVA) with Tukey's post-hoc test. Values of $p$ below 0.05 were considered statistically significant.

\section{Results}

\section{Rheological characterisation of sulphated alginate gels}

$\mathrm{Alg} / \mathrm{S}-\mathrm{Alg}$ gels were prepared and the storage modulus (G) was measured to evaluate gelling kinetics and the final stiffness of the gels. Using mixtures of highly sulphated alginate $(\mathrm{S}-\mathrm{Alg}, \mathrm{DS}=0.90)$ and $\mathrm{Alg}$ a prominent decrease in gel stiffness was observed with increasing S-Alg content (Fig. 1a). Furthermore, the introduction of highly sulphated alginate was shown to have a negative effect on gelling, 


\begin{tabular}{|r|c|c|}
\hline \multicolumn{1}{|l|}{ Sample } & S-Alg content & E (Pa) \\
\hline Alg (2 \% w/v) & $0 \%$ & 6650 \\
\hline Alg (1.2 \% w/v) & $0 \%$ & 2530 \\
\hline \multirow{2}{*}{ S-Alg / Alg } & $20 \%$ & 2330 \\
\cline { 3 - 4 } & $40 \%$ & 1580 \\
\cline { 2 - 3 } & $60 \%$ & 803 \\
\hline S-Alg DS = 0.20 & $80 \%$ & 343 \\
\hline S-Alg DS = 0.28 & $100 \%$ & 1470 \\
\hline S-Alg DS = 0.36 & $100 \%$ & 1310 \\
\hline
\end{tabular}
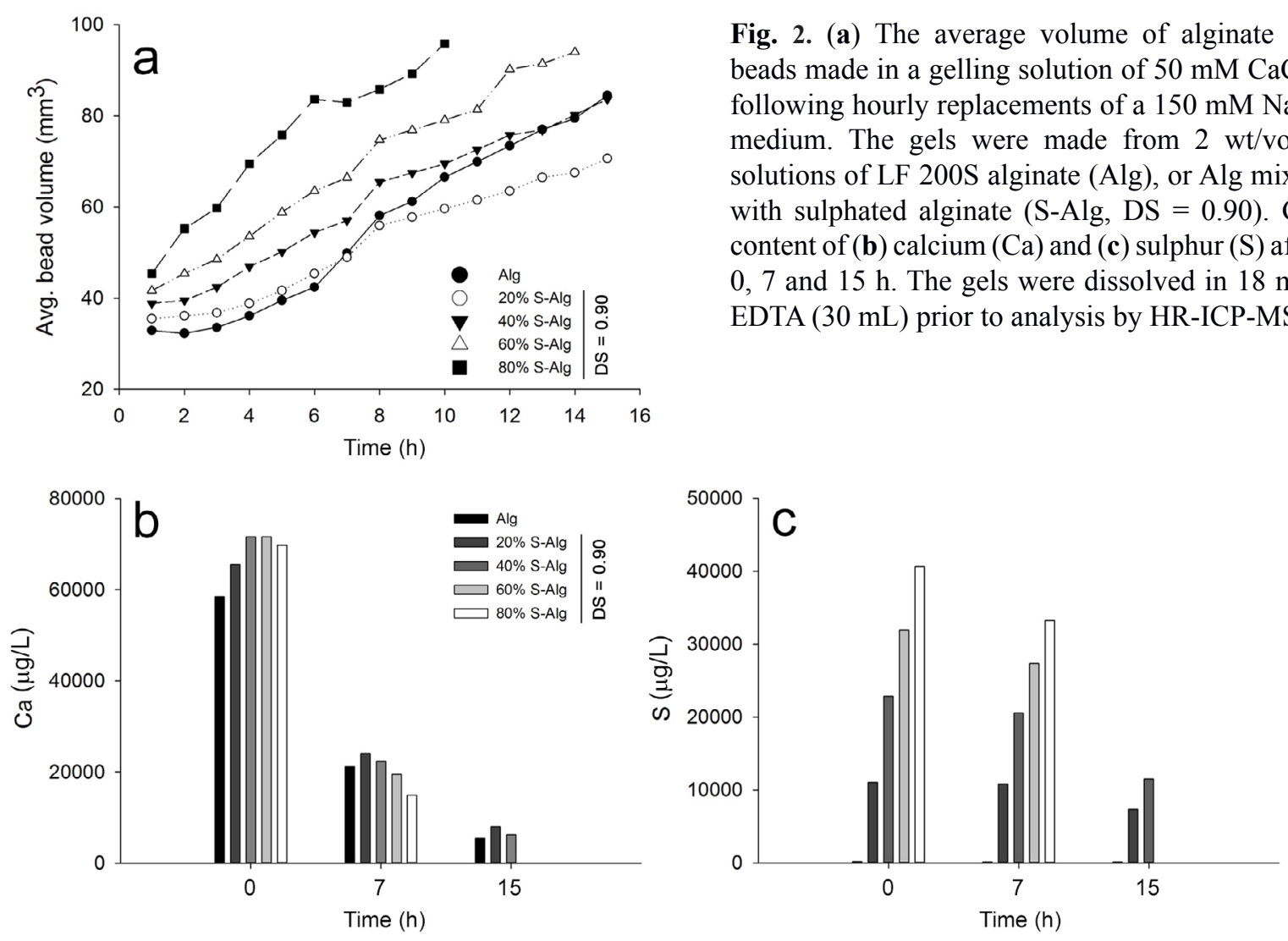

Table 1. Young's modulus (E) of gels prepared from mixtures of alginate (Alg) and sulphated alginates $(\mathrm{S}-\mathrm{Alg}, \mathrm{DS}=0.90)$, or from exclusively S-Alg with increasing degrees of sulphation. Gelation occurred over $15 \mathrm{~h}$ using $30 \mathrm{mM} \mathrm{CaCO}_{3}$ and $60 \mathrm{mM}$ GDL. All sulphated alginate gels were prepared from a total polysaccharide solution of $2 \% \mathrm{w} / \mathrm{v}$ and the modulus was measured by oscillatory shear deformation.

Fig. 2. (a) The average volume of alginate gel beads made in a gelling solution of $50 \mathrm{mM} \mathrm{CaCl}_{2}$, following hourly replacements of a $150 \mathrm{mM} \mathrm{NaCl}$ medium. The gels were made from $2 \mathrm{wt} / \mathrm{vol} \%$ solutions of LF $200 \mathrm{~S}$ alginate (Alg), or Alg mixed with sulphated alginate $(\mathrm{S}-\mathrm{Alg}, \mathrm{DS}=0.90)$. Gel content of (b) calcium (Ca) and (c) sulphur (S) after 0,7 and $15 \mathrm{~h}$. The gels were dissolved in $18 \mathrm{mM}$ EDTA $(30 \mathrm{~mL})$ prior to analysis by HR-ICP-MS. as excluding S-Alg resulted in increased gel stiffness by approximately $1000 \mathrm{~Pa}$ for a $1.2 \mathrm{wt} / \mathrm{vol} \%$ solution of Alg (Table 1). Using pure sulphated alginates, stable gels were formed at DS $=0.20$ and 0.28 with stiffness similar to that of $40 \% \mathrm{~S}-\mathrm{Alg}(\mathrm{DS}=0.90)$. At $\mathrm{DS}=0.36$ there was observed an approximately tenfold decrease in stiffness resulting in fragile gels (Fig. 1b), while samples with DS $>0.50$ did not form true gels under the present conditions (not shown).

\section{Swelling properties of sulfated alginate gels}

\section{Calcium-crosslinked gel}

There was observed a difference in the initial size of the calcium gels, where a higher S-Alg content was associated with a larger volume (Fig. 2a). The Alg control and the 20-60\% S-Alg gels displayed initially similar swelling rates following hourly replacements of the saline, while the volume increase of the $80 \% \mathrm{~S}-\mathrm{Alg}$ gels was considerably higher, causing gel disruption after $10 \mathrm{~h}$. After $6 \mathrm{~h}$ the swelling of the Alg gels accelerated and eventually gained a similar volume to that of the $40 \%$. The $20 \%$ S-Alg gels displayed considerably less swelling and remained intact for longer than all other samples, a trend also observed for S-Alg samples of lower DS (not shown). Gels were retrieved after 0,7 and $15 \mathrm{~h}$, and the relative concentrations of calcium and sulphur in the gels are shown in Fig. 2b and c, respectively. The calcium content of all gels was reduced by approximately $60 \%$ from 0 to $7 \mathrm{~h}$. A higher concentration of calcium was detected in the S-Alg samples compared to Alg at $0 \mathrm{~h}$, which was also observed at 7 and $15 \mathrm{~h}$ for the $20 \%$ and $40 \% \mathrm{~S}-\mathrm{Alg}$ samples, whereas the $60 \%$ and $80 \%$ S-Alg gels had dissolved at $15 \mathrm{~h}$. Furthermore, there was a decrease in sulphur over time, indicating loss of sulphated alginate during swelling. The $20 \% \mathrm{~S}-\mathrm{Alg}$ gels displayed no material loss at $7 \mathrm{~h}$, whereas the sulphur content was reduced by approximately one third at $15 \mathrm{~h}$. 

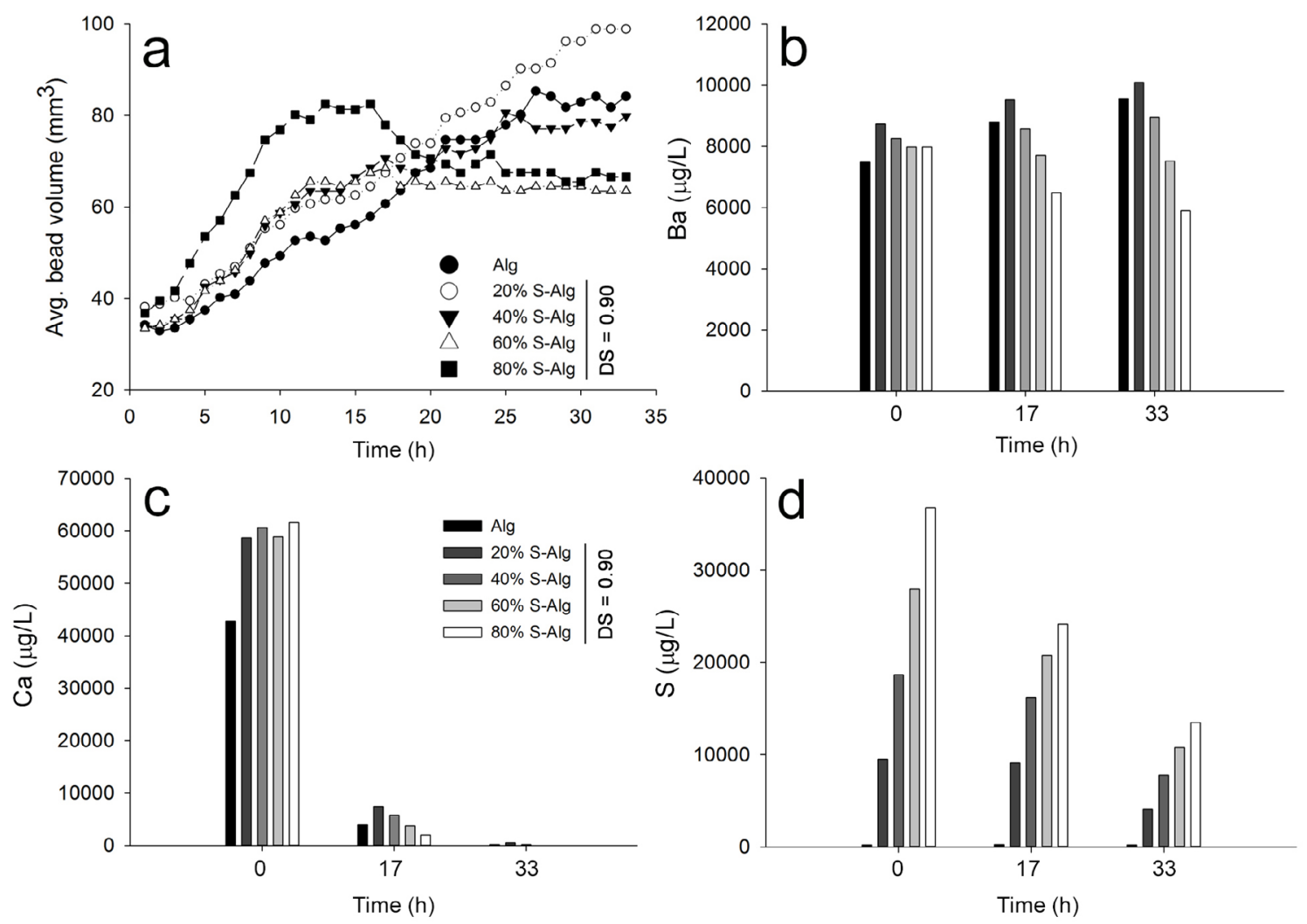

Fig. 3. (a) The average volume of alginate gel beads made in a gelling solution of $50 \mathrm{mM} \mathrm{CaCl}$ and $1 \mathrm{mM}$ $\mathrm{BaCl}_{2}$, following hourly replacements of a $150 \mathrm{mM} \mathrm{NaCl}$ medium. The gels were made from $2 \mathrm{wt} / \mathrm{vol} \%$ solutions of LF 200S alginate (Alg), or Alg mixed with sulphated alginate (S-Alg, DS =0.90). Gel content of (b) barium (Ba), (c) calcium (Ca) and (d) sulphur (S) after 0, 17 and $33 \mathrm{~h}$. The gels were dissolved in $36 \mathrm{mM}$ EDTA $(30 \mathrm{~mL})$ prior to analysis by HR-ICP-MS.

Calcium-barium-crosslinked gels

The calcium-barium gels displayed overall higher stability than the calcium gels and were monitored over $33 \mathrm{~h}$ (Fig. 3 a), with elemental analysis of the gels carried out after 0,17 and $33 \mathrm{~h}$. The initial gel volume was similar for all samples; the swelling rate was the highest for $80 \% \mathrm{~S}-\mathrm{Alg}$ and lowest for the Alg sample. Past $17 \mathrm{~h}$ a decrease in gel volume was measured for the $80 \%$ S-Alg samples, resulting in lower volumes than the remaining samples at $33 \mathrm{~h}$. A high degree of barium retention was observed in all samples (Fig. 3b), contrasting with the steep decrease in calcium (Fig. 3c). Similar to the calcium gels, higher initial concentrations of gelling ions were detected in the calcium-barium gels containing sulphated alginate compared with the Alg control.

Gels were additionally prepared from exclusively S-Alg with varying degrees of sulphation. When using a gelling bath of $50 \mathrm{mM} \mathrm{CaCl}_{2}$, the gels took on a highly inhomogeneous shape and were disrupted overnight. Gels were successfully prepared with the $\mathrm{CaCl}_{2} / \mathrm{BaCl}_{2}$ gelling bath, but increased rapidly in volume and disrupted after fewer replacements compared with gels containing unmodified alginate (not shown).

Visualisation of chondrocyte viability, morphology and chondrogenic redifferentiation in sulphated alginate gels

As the inclusion of unmodified alginate resulted in increased stability of sulphated hydrogels, we aimed to explore whether mixed gels demonstrate similar biological effects on encapsulated chondrocytes as pure S-Alg gels, as well as the influence of varying S-Alg content. For the pure S-Alg gels, a sulphation degree of 0.32 was chosen, whereas the mixed $80 \% \mathrm{~S}$-Alg sample was excluded due to the high swelling potential. Live/dead staining of encapsulated chondrocytes showed good viability after one week and no significant differences between unmodified alginate and gels containing sulphated alginate (Fig. 4a). Phalloidin-rhodamine staining showed formation of filopodia from cells encapsulated in sulphated alginate gels, most prominently for the gel containing exclusively sulphated alginate $(\mathrm{S}-\mathrm{Alg} \mathrm{DS}=0.32)$, whereas the cells in the unmodified alginate displayed a spherical morphology after one week culture (Fig. 4b). Filopodia were also observed in the mixed gels, with no apparent differences based on S-Alg content. The differences in cellular morphology between chondrocytes encapsulated within sulphated alginate or unmodified gels became much more evident after 3 weeks of culture with chondrogenic induction. Chondrocytes in sulphated alginate showed extensive spreading throughout the gel whereas the chondrocytes in unmodified alginate still revealed round cell morphology (Fig. 5a).

We further investigated the chondrogenic redifferentiation of chondrocytes within Alg or S-Alg $(\mathrm{DS}=0.32)$ gels. Immunohistological staining of the chondrocytes in Alg or S-Alg gels revealed collagen II deposition under both conditions (Fig. 5b). In the Alg 

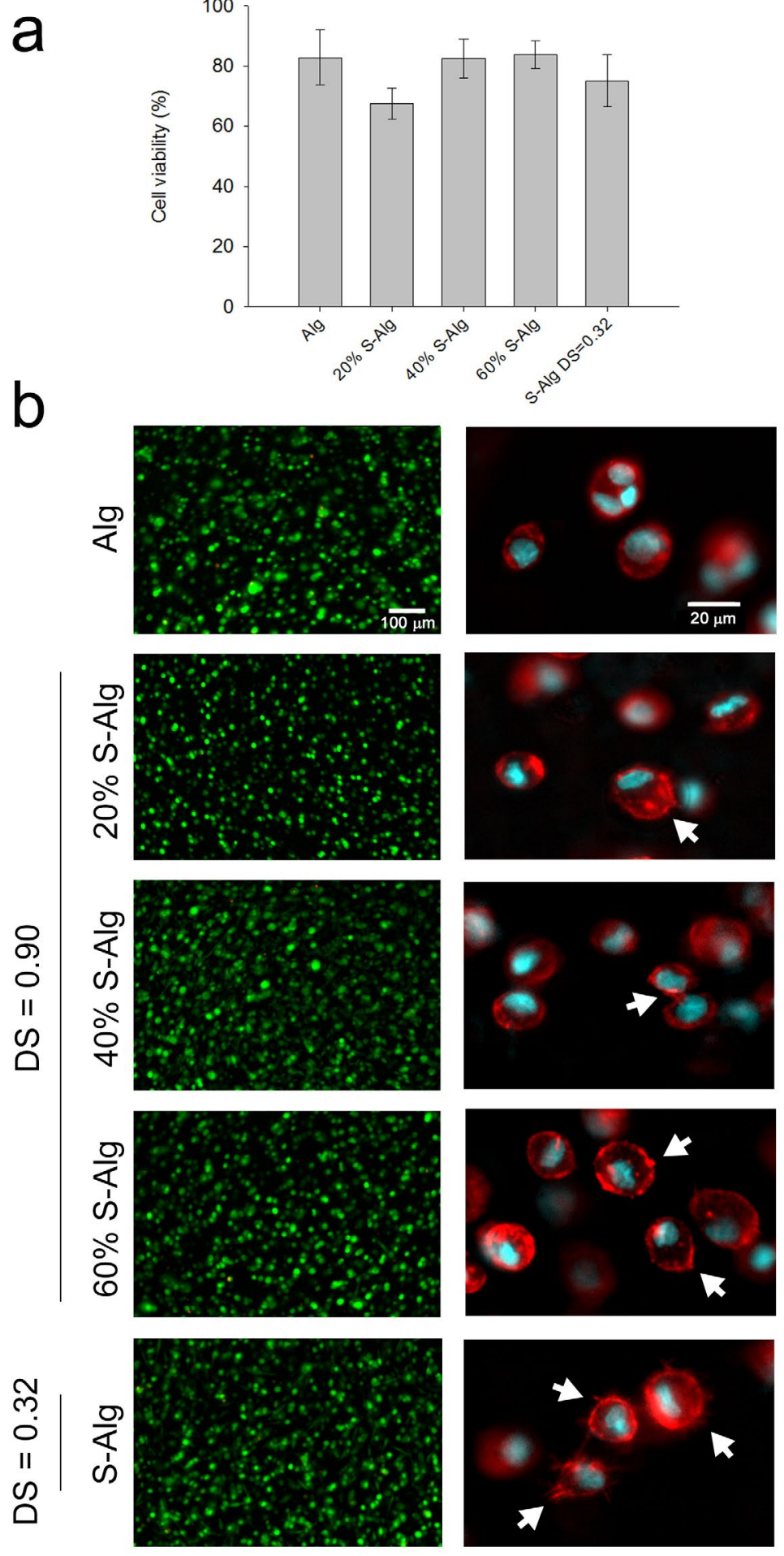

Fig. 4. (a) Quantification of chondrocyte viability in hydrogels of alginate (Alg), sulphated alginate $(\mathrm{S}-\mathrm{Alg} \mathrm{DS}=0.32)$ or mixtures of Alg and S-Alg (DS $=0.90)$ after 1 week. (b) Fluorescence imaging of condrocytes encapsulated in calcium gels of alginate (Alg), sulphated alginate $(\mathrm{DS}=0.32)$ or sulphated alginate (DS $=0.90)$ mixed with unmodified alginate. Cells were stained with calcein and ethidium homodimer for viability assessment (left), or with phalloidinrhodamine for cell morphology (right). Arrows indicate protruding filopodia from the plasma membrane. gels, the collagen was highly concentrated around the edges of the gels, whereas the S-Alg gels promoted a more homogeneous matrix deposition. Collagen I deposition, on the other hand, was much less in the sulphated hydrogels compared to the unmodified alginate. Collagen I was similarly deposited mainly on the edge of the Alg gels; however, the thickness was higher than seen for the collagen II staining (Fig. 5b). In S-Alg gels, a slight collagen I deposition was observed in the edges and mainly excluded from the collagen II-positive core of the gels (Fig. $5 \mathbf{b})$. The deposition of collagen II was dependent on the
TGF- $\beta 3$ induction of the chondrocytes and no collagen II staining was detected when the chondrocytes were grown in TGF- $\beta 3$-free control medium (not shown).

\section{Inflammatory stimulation of encapsulated} chondrocytes with IL-1及

Gene expression of inflammatory markers

Gene expression of IL-6, IL-8, COX-1, COX-2, MMP13 (collagenase-3) and ADAMTS-5 was quantified in the encapsulated chondrocytes following 24 or $48 \mathrm{~h}$ stimulation with IL-1 $\beta$ (Fig. 6). The gene expression was 
a

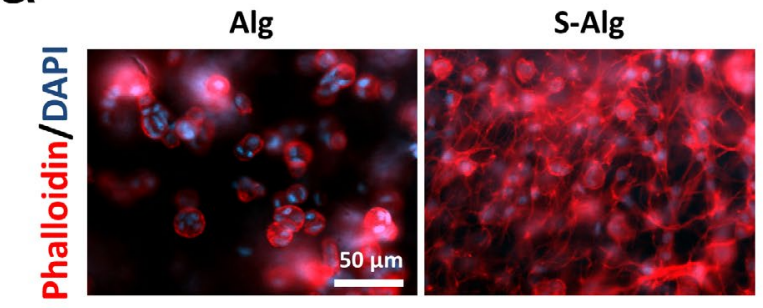

b

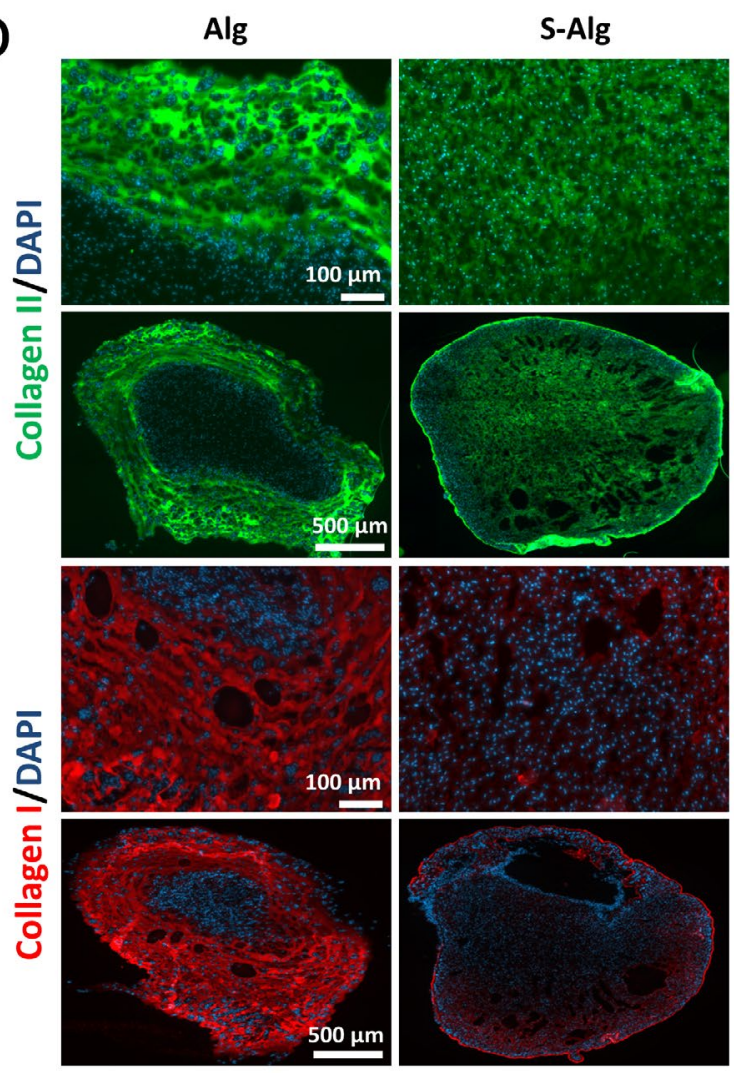

Fig. 5. (a) Phalloidin-rhodamine staining of chondrocytes encapsulated in alginate (Alg) or sulphated alginate $(\mathrm{S}-\mathrm{Alg}, \mathrm{DS}=0.32$ ) after 3 weeks. (b) Immunofluorescence imaging of collagen II (green) and collagen I (red) deposition in Alg and S-Alg (DS = 0.32) gels. DAPI (blue) was used as counterstain for cells.

generally lower after $48 \mathrm{~h}$ compared with $24 \mathrm{~h}$, suggesting a possible negative feedback regulation of the inflammatory response. Interleukins IL-6 and IL-8 were strongly induced by IL- $1 \beta$ and displayed similar expression trends in the different gels. Compared to the Alg control IL-6 and IL-8 induction was significantly reduced in all S-Alg gels, most potently in the $20 \% \mathrm{~S}-\mathrm{Alg}(\mathrm{DS}=0.90)$ sample and the gel containing exclusively S-Alg ( $\mathrm{DS}=0.32)$. COX-2 expression was induced in alginate gels and significantly reduced in all S-Alg gels, displaying a similar trend as IL-6 and IL-8. No inhibitory effect of sulphated alginates was found on the IL-1 $\beta$-induced expression of MMP-13, whereas ADAMTS-5 was significantly suppressed in the S-Alg gels. Gene expression was for IL-6, IL-8, COX-2 and ADAMTS-5 significantly lower in the $20 \% \mathrm{~S}-\mathrm{Alg}$ gel compared to the $60 \% \mathrm{~S}-\mathrm{Alg}$ gel. Variable trends in gene expression were observed in the absence of IL- $1 \beta$ stimulation, although it was generally reduced by the presence of sulphated alginate (not shown).

Of the collagenases, collagenase 3 (MMP-13) has the broadest substrate specificity, cleaving types I, II, III, IV, X, and XIV collagen, gelatin, and aggrecan (1012). MMP-13 exhibits the highest activity (kcat/Km) toward CII, the pre-dominant collagen in cartilage (13). Compared with MMP-1 expression, MMP-13 expression is somewhat restricted. In normal physiology, osteoblasts and chondrocytes express MMP-13 in developing bone (1416). In pathologic conditions, the enzyme is expressed by a variety of cell types, including OA chondrocytes $(5,17-20)$, rheumatoid synovium (21-23), squamous cell carcinomas $(24,25)$, breast cancer $(26,27)$, chondrosarcomas $(28)$, fibroblasts in chronic wounds $(29,30)$, and macrophages in atherosclerotic plaques (31). Presumably, expression of MMP-13 is more restricted than expression of MMP-1, because the broad substrate specificity of MMP-13 makes it potentially more damaging to normal tissues.

\section{Protein expression of inflammatory markers}

Protein expression in chondrocytes was studied by Western blotting after $24 \mathrm{~h}$ IL- $1 \beta$ stimulation for NF- $\kappa B$, phosphorylated NF- $\kappa \mathrm{B}(\mathrm{pNF}-\kappa \mathrm{B})$ and phosphorylated p38-MAPK (pp38-MAPK), and after $48 \mathrm{~h}$ stimulation for COX-2 (Fig. 7).

Phosphorylated NF- $\kappa \mathrm{B}$ was strongly reduced in all sulphated alginate gels, and total NF- $\kappa \mathrm{B}$ was reduced with increasing S-alg content in the gels. Interestingly, NF- $\kappa \mathrm{B}$ was clearly expressed in the $20 \% \mathrm{~S}$-Alg sample whereas phosphorylation ( $\mathrm{pNF}-\kappa \mathrm{B})$ was barely detectable in the same sample. p38-MAPK is involved in the activation of $\mathrm{NF}-\kappa \mathrm{B}$ and its phosphorylation was found to be similarly suppressed in the sulphated alginate gels as a function of sulphation level. COX-2 is a downstream marker compared to NF- $\kappa \mathrm{B}$ and $\mathrm{p} 38-\mathrm{MAPK}$ and was therefore measured after $48 \mathrm{~h}$ IL-1 $\beta$ stimulation. COX-2 protein was strongly induced in alginate gels and significantly reduced in all sulphated alginate gels. S-Alg DS $=0.32$ displayed a slightly more potent reduction, whereas the effect was not markedly different between the mixed gels.

\section{IL-1及 interaction with sulphated alginate hydrogels}

We further aimed to investigate whether the sulphated microenvironment led to an increased entrapment of IL$1 \beta$, relating to the suppression of inflammatory signalling in the chondrocytes encapsulated in the sulphated hydrogels. For this purpose, IL-1 $\beta$ was immobilised in gels of Alg, S-Alg (DS =0.32), or mixtures of Alg and $\mathrm{S}-\mathrm{Alg}(\mathrm{DS}=0.90)$, followed by 24 or $48 \mathrm{~h}$ incubation in physiological saline. After both 24 and 48 h incubation, the sulphated gels showed a greater retention of IL-1 $\beta$ compared to the non-sulphated alginate gels (Fig. 8). After $24 \mathrm{~h}$ incubation, the increase in IL- $1 \beta$ retention followed a clear dose-responsive trend with the increase in sulphated alginate content. After $48 \mathrm{~h}$ incubation, the trend was less pronounced where the $40 \%$ and $60 \%$ mixtures showed similar IL- $1 \beta$ retention but still significantly higher than the $20 \%$ mixtures and the non-sulphated samples. 

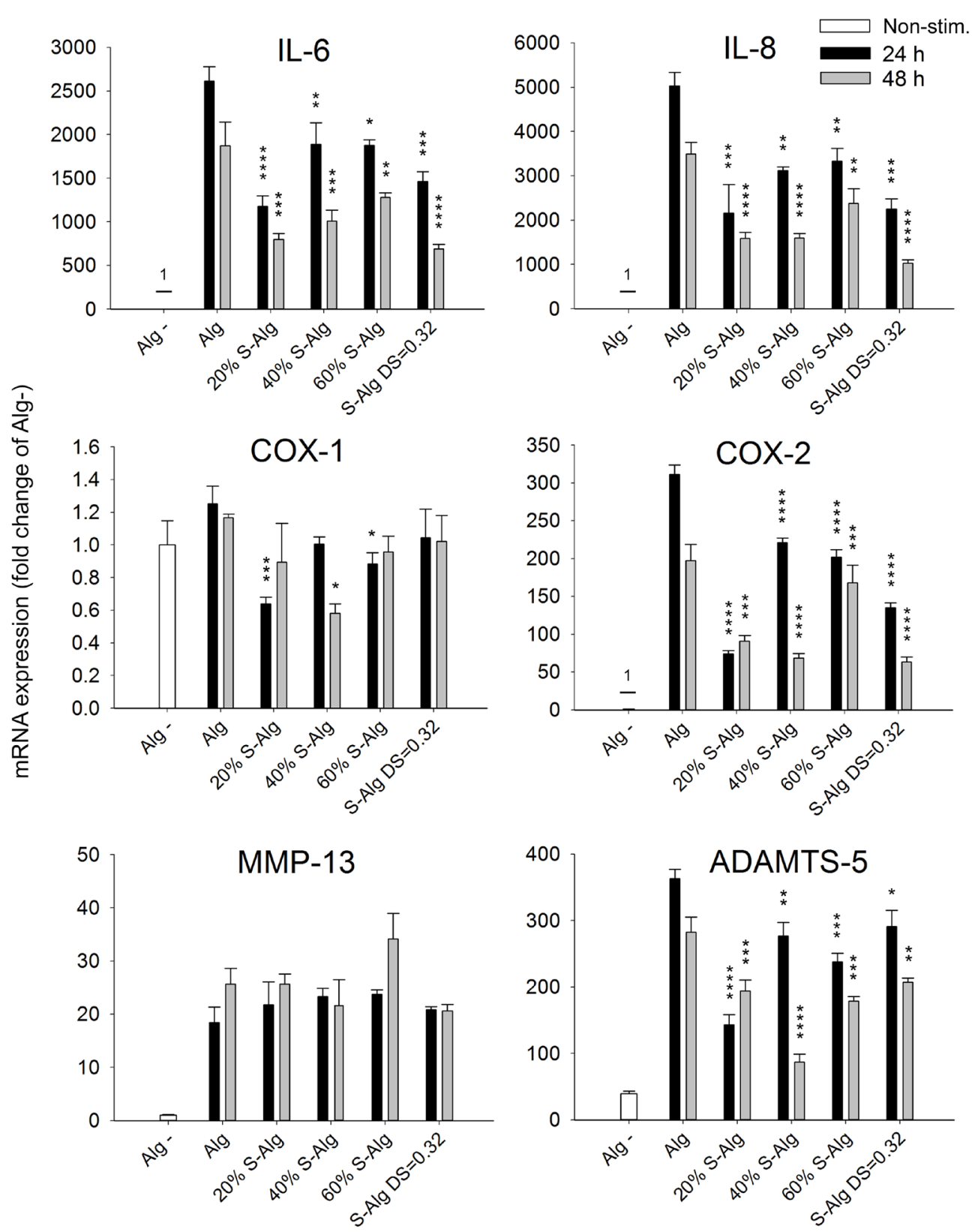

Fig. 6. mRNA expression of IL-6, IL-8, COX-1, COX-2, MMP-13 and ADAMTS-5 in chondrocytes after 24 and $48 \mathrm{~h}$ stimulation with IL-1 $\beta$. The cells were encapsulated in calcium gels of alginate (Alg), sulphated alginate $(\mathrm{S}-\mathrm{Alg}, \mathrm{DS}=0.32$ ) or mixtures of Alg and S-Alg (DS $=0.90)$, and cultured for one week prior to IL$1 \beta$ stimulation. Non-stimulated alginate gels are denoted by Alg-. Significant values are given as $p<0.05(*)$, $p<0.01(* *), p<0.001(* * *)$ and $p<0.0001(* * * *)$ compared to Alg at the same time point, and the data are expressed as the mean value of 3 samples \pm s.d.

\section{Discussion}

Sulphated alginate hydrogels were evaluated, in the present study, for applications in cartilage engineering, through characterisation of physical and biological properties. The elastic modulus and swelling potential of the hydrogels were initially studied. Furthermore, human chondrocytes were encapsulated in sulphated alginate gels and stimulated with IL-1 $\beta$, to study anti-inflammatory properties of the scaffolds and the influence of varying the sulphated alginate content.

For the rheological studies, hydrogels were prepared using GDL to promote a gradual release of $\mathrm{Ca}^{2+}$ from evenly distributed $\mathrm{CaCO}_{3}$. This resulted in a more homogeneous gel network compared to $\mathrm{CaCl}_{2}$ crosslinking, particularly for large volumes of alginate solutions, as was the case with the rheological measurements. Furthermore, this "internal" gelation procedure allows formation of hydrogels in situ from injectable solutions, and may show promise for novel tissue engineering strategies (Sandvig et al., 2015). Measurement of the storage modulus in gels of exclusively $\mathrm{S}$-Alg indicated a threshold in DS for the formation of stable crosslinks by gelation with $\mathrm{CaCO}_{3}$. Previous studies have shown that the number of consecutive guluronate units required for stable junction zones is approximately 8 for calcium alginate gels (Stokke et al., 1993). As the sulphation follows a random pattern, sequences of nonsulphated monosaccharides able to form stable cross-links 


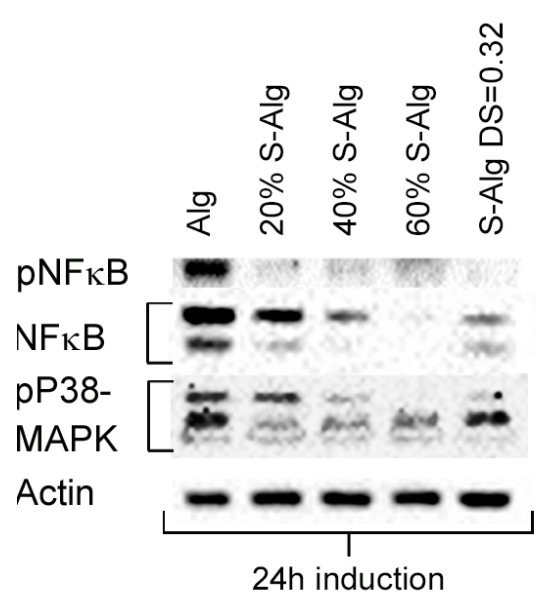

$24 \mathrm{~h}$ induction

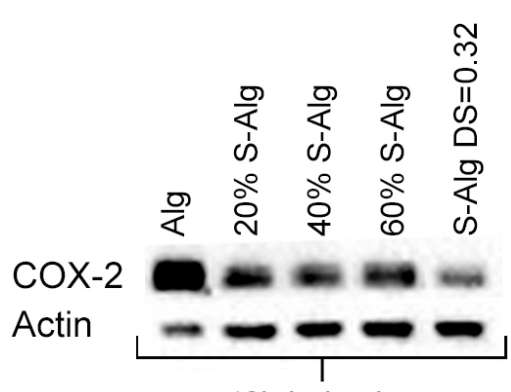

$48 \mathrm{~h}$ induction

Fig. 7. Western blot following IL-1 $\beta$ stimulation of chondrocytes encapsulated in alginate $(\mathrm{Alg})$, sulphated alginate $(\mathrm{S}-\mathrm{Alg}, \mathrm{DS}=0.32)$ or mixtures of Alg and S-Alg $(\mathrm{DS}=0.90)$. Left: $\mathrm{NF} \kappa \mathrm{B}$, phosphorylated (activated) NF $\kappa$ B and p38-MAPK after $24 \mathrm{~h}$ stimulation, right: $\mathrm{COX}$ 2 after 48 h. stimulation.

Fig. 8. Retention of IL-1 $\beta$ immobilised in hydrogels of alginate (Alg), sulphated alginate (S-Alg $\mathrm{DS}=0.32$ ) or mixtures of Alg and S-Alg $(\mathrm{DS}=0.90)$ following 24 or $48 \mathrm{~h}$ incubation in a saline medium, quantified by ELISA. Significant values are given as $p<0.05\left(^{*}\right)$, $p<0.01(* *)$ and $p<0.001$ (***) compared to Alg at the same time point, and the data are expressed as the mean value of 3 samples \pm s.d.

are expected to be found at low sulphation degrees (Arlov et al., 2014). The number of $\mathrm{G}$ monosaccharides required for stable junction formation is lower for $\mathrm{Ba}^{2+}$ than $\mathrm{Ca}^{2+}$ (Stokke et al., 1991), and the elastic moduli of sulphated alginate gels can thus be increased by saturation with $\mathrm{BaCl}_{2}$ following gelation. The molecular weight of the alginates is a significant factor and it must be noted that the sulphation reaction is highly acidic, leading to some depolymerisation. In the present study an approximately 30-50\% reduction in the average molecular weight was measured for the various degrees of sulphation. While the storage modulus of alginate gels is highly dependent on the MW, the present results indicate that the density of the sulphate groups is a more significant factor as the DS $=0.36$ sample had similar molecular weight but markedly lower stiffness than the DS $=0.28$ gel. Inclusion of the unmodified Alg in the S-Alg gels results in increased gel stiffness, while allowing incorporation of sulphated alginates with a high DS, which may be desirable to strengthen electrostatic protein interactions.

Inclusion of unmodified alginate also improved the osmotic stability of sulphated alginate gels. Swelling of alginate gels occurs when gelling ions in the cross-linking junction zones are replaced with non-gelling cations such as sodium, partially dissolving the alginate and weakening the gel network. Despite the prominent reduction in stiffness, gels with a 20-40 \% S-Alg content displayed similar swelling rates as the Alg control. As indicated by the elemental analysis of the dissolved gels, the higher charge density introduced by S-Alg leads to increased binding and retention of gelling ions. A greater retention of gelling ions decreases the osmotic potential to the surrounding medium, presumably slowing sodium influx and replacement of calcium. Whereas leakage of sulphated alginate was observed in the mixed gels following consecutive saline changes and swelling, this was not expected for hydrogels used for chondrocyte encapsulation due to the presence of $\mathrm{CaCl}_{2}$ in the incubation medium and the fact that no swelling was observed in the gels over the course of the study. For long term stability of gels with a high content or consisting exclusively of sulphated alginate it is therefore recommended to include $\mathrm{CaCl}_{2}$ in the storage medium. Recent studies have also explored the use of barium or strontium as cross-linking ions. Although barium is highly toxic to cells, a low concentration in implanted alginate hydrogels may prove safe for encapsulated cells and surrounding tissues, due to the strong association with alginate preventing leakage (Mørch et al., 2006; Mørch et al., 2012). 


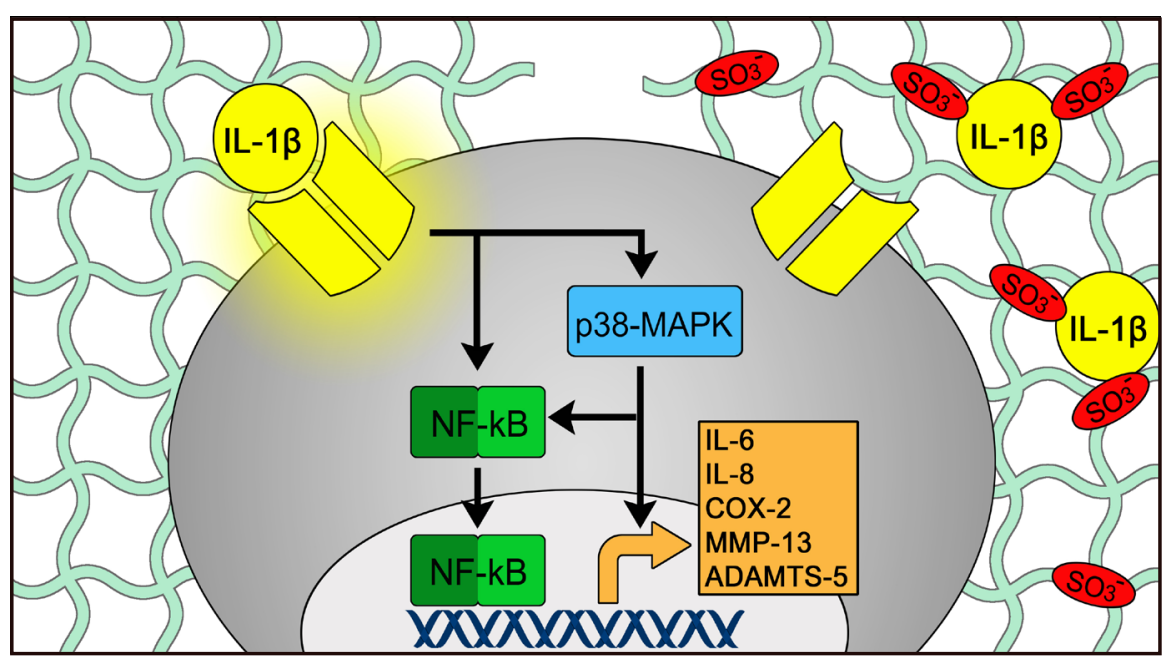

Fig. 9. Schematic depiction of the proposed anti-inflammatory effects by sulphated alginates on encapsulated chondrocytes. Stimulation of chondrocytes with IL-1 $\beta$ induces gene expression of inflammatory and catabolic markers, mediated by NF- $\mathrm{B}$ and $\mathrm{p} 38$-MAPK signalling pathways. Sulphation promotes interaction with IL- $1 \beta$ and thus providing a protective microenvironment by sequestering the cytokine in the gel network and inhibiting receptor activation.

We recently showed that the presence of sulphated alginate stimulates proliferation and spreading of bovine chondrocytes in a dose-responsive manner to the sulphate content (Öztürk et al., 2016), which was consistent with the results of the present study using passaged human chondrocytes. The formation of filopodia has previously been found to be mediated by integrin beta 1 interaction with sulphated alginate, providing cell attachment points and potentially increasing proliferation through stimulated Cyclin D gene expression (Mhanna et al., 2014). There was, in the present study, no observable relation between cell viability and morphology and the mechanical properties/sulphate content of the gels. The stiffness of the gel is, however, expected to have a greater influence on long-term expansion of tissues and deposition of extracellular matrix, thus requiring additional studies with longer cultivation times. The non-sulphated Alg gels displayed highly concentrated deposition of collagen around the edges of the gels, whereas a more homogeneous matrix deposition was observed in the S-Alg gels. This can be attributed to a poorer entrapment of growth factors in the Alg gels, consistent with previous findings (Öztürk et al., 2016). Furthermore, chondrocytes showed much less deposition of collagen I in S-Alg gels compared to Alg indicating that the sulphated gels favour a more native-like phenotype during chondrogenic redifferentiation with a more homogeneous distribution of the produced matrix. These results are also in line with our previous findings where we showed that sulphation in the microenvironment prevented dedifferentiation of non-passaged bovine chondrocytes during 3D expansion by suppression of collagen I (Öztürk et al., 2016).

RNA analysis of inflammatory markers showed significant decreases in IL-6, IL-8, COX-2 and ADAMTS-5 in S-Alg gels compared with the Alg control. COX-1 was not significantly induced by IL- $1 \beta$ as it is considered a "housekeeping" gene involved in continuous prostaglandin production in homeostatic functions, whereas $\mathrm{COX}-2$ is more tightly regulated and inducible by inflammatory cytokines (Crofford, 1997). MMP-13 expression is tightly regulated, presumably due to its broad substrate specificity and thus can severely affect cartilage matrix. MMP-13 is induced in chondrocytes by inflammatory cytokines in osteoarthritis, and modulated by several intracellular factors including NF- $\kappa \mathrm{B}$ and $\mathrm{p} 38$-MAPK (Mengshol et al., 2000; Vincenti and Brinckerhoff, 2002). FGF-2 has been demonstrated to have a chondroprotective effect (Chia et al., 2009), and we recently showed that sulphated alginates decrease the expression of MMP-13 and ADAMTS-5 in chondrocytes by mediating FGF signalling (Öztürk et al., 2016). In the present study, sulphated alginate suppressed the expression of MMP-13 in non-stimulated chondrocytes but not following IL-1 $\beta$ stimulation, indicating different signalling mechanisms during intrinsic expression compared to inflammatory induction. Alternatively, as the sulphated alginate matrix does not completely abolish IL-1 $\beta$ induction, MMP-13 expression may only require a low level of IL-1 $\beta$ signalling followed by amplification and regulation primarily by intracellular mechanisms. In the absence of IL-1 $\beta$ stimulation the expression of all studied markers, including MMP-13 and COX-1, was nearly abolished in the $20 \%$ S-Alg gel. Thus, the sulphated alginate matrices may additionally suppress inflammatory and catabolic markers in a non-inflamed setting.

Analysis of protein expression showed a strong reduction in the total $\mathrm{NF}-\kappa \mathrm{B}$ and $\mathrm{COX}-2$ protein levels in the sulphated alginate gels, as well as inhibition of the phosphorylation of NF- $\mathrm{KB}$ and p38-MAPK. Preincubation with soluble heparin and chondroitin sulphate has previously been shown to dampen the inflammatory response in cells stimulated with IL-1 $\beta$, correlated with reduced NF- $\mathrm{NB}$ signalling, but the mechanisms of action by the polysaccharides are not clear (Hochart et al., 2006; Jomphe et. al., 2008; Legendre et al., 2008). Sulphated alginate has previously been demonstrated to bind IL-6 (Freeman et al., 2008), and we recently found 
that incubation of sulphated alginate gels in human whole blood lead to decreased levels of inflammatory cytokines, including IL-1 $\beta$, IL-6, IL-8 and TNF, as well as inhibition of the complement cascade (Arlov et al., 2014; Arlov et $a l ., 2016)$. IL-1 $\beta$ has been shown to bind several acidic polysaccharides, in particular highly sulphated heparin (Ramsden and Rider, 1992). Furthermore, sulphated glycosaminoglycans present on the cell surface contribute to cell signalling by immobilising growth factors, cytokines and other signalling molecules in the vicinity of the cells (Linhardt and Toida, 2004; Parish, 2006; Shute, 2012). Chondrocytes in an inflammatory state release immobilised cytokines through remodelling of the extracellular matrix, thus propagating the inflammatory response. As demonstrated in the present study, sulphated alginate interacts with IL-1 $\beta$ and the sequestration of cytokines in the extracellular environment may thus prevent inflammatory induction of the encapsulated chondrocytes (Fig. 9). Humans do not express enzymes that degrade alginate, and while additional studies are required to assess the in vivo stability of sulphated alginates, it is intuitive that they are not degraded by the same mechanisms as for sulphated glycosaminoglycans. Resistance to enzymatic depolymerisation may provide increased stability of the scaffold, with less release of signal molecules by matrix turnover and thus potentially a more long-term antiinflammatory effect. Depending on the application, the degradability of the alginate hydrogels can be influenced by exploring alternative gelation strategies, or by functional modifications such as partial periodate oxidation rendering the alginate susceptible to depolymerisation.

In the present study, there was no clear doseresponse between the sulphated alginate content and the anti-inflammatory effects. NF- $\kappa \mathrm{B}$ protein and the phosphorylation of p38-MAPK were found to decrease with increasing sulphate content of the gels, whereas gene expression of IL- 6 , IL- 8 and COX-2 was generally higher in $60 \% \mathrm{~S}-\mathrm{Alg}$ gels compared with $20 \% \mathrm{~S}-\mathrm{Alg}$. These results may be influenced by a trade-off effect where increased electrostatic interaction at higher sulphation levels are counteracted by a more porous network structure with increased diffusion of extracellular signal molecules. Alternatively, as sulphated alginates may interact with a large variety of extracellular factors, the increased level of sulphation may have additional cytokine-mediated effects acting through alternative mechanisms.

Interestingly, the present results and previous findings on growth factor signalling (Öztürk et al., 2016) indicate dual roles for sulphated alginates in signalling, through suppressing and promoting cellular interaction with soluble factors. Although this may be attributed to nonspecific binding of S-Alg to proteins, most interactions between sulphated GAGs and their ligands are similarly believed to have a low degree of specificity (Lindahl, 2014; Lindahl and Li, 2009). For FGF-2 signalling heparan sulphate acts as a co-receptor forming a tertiary complex with the ligand and receptor (Spivak-Kroizman et al., 1994), whereas sulphated polysaccharides may conversely inhibit signalling by associating with the receptor-binding region of cytokines and/or preventing conformational changes (Johnson et al., 2005). Additionally, signalling events may be directed through temporal regulation of structural subtypes of sulphated GAGs, which can explain their pleiotropic properties in vivo (Dyck and KarimiAbdolrezaee, 2015; Mikami and Kitagawa, 2013). As the monosaccharide sequence of alginate can be predictably altered utilising epimerases (Ertesvåg, 2015) and the sulphation degree readily tuned, these structural variations can be employed to gain a greater understanding of the interactions between the matrix and soluble factors, and potentially tailor sulphated alginate gels to allow a regenerative environment for cartilage while suppressing key inflammatory events.

\section{Conclusions}

In the present study, we investigated the physical characteristics of sulphated alginate gels and the biological effects on human chondrocytes in the presence of inflammatory induction. Sulphation of alginate resulted in a prominent decrease in the storage modulus, and an increase in swelling of the gel network. Encapsulation of chondrocytes in sulphated alginate gels suppressed the expression and activation of NF- $\kappa$ B following IL- $1 \beta$ stimulation, causing an inhibition of inflammatory and catabolic responses. We propose that sulphated alginates exert their anti-inflammatory properties by binding and sequestering inflammatory mediators, namely IL-1 $\beta$ in the present study. Mixing unmodified alginate with a low content of highly sulphated alginate resulted in improved gel stability and similar anti-inflammatory activity compared with pure sulphated alginate gels, and may allow more predictable tuning of gel properties. The potent protection by the gel microenvironment against inflammatory induction of chondrocytes, presumably due to sequestration of inflammatory cytokines in the gel network, reveals an important role of GAG-mimicking sulphate moieties and a promising direction for cartilage tissue engineering.

\section{Acknowledgements}

Ø.A. and G.S.-B. were funded by the Norwegian Research Council (221576). E.Ö. and M.Z.W. were funded by Swiss National Science Foundation (315230_159783 and 315230_143667), Center for Applied Biotechnology and Molecular Medicine (CABMM) and FIFA/F-MARC (FIFA Medical Assessment and Research Center). The authors would like to acknowledge Finn L. Aachmann, NTNU Dept. of Biotechnology, for NMR analysis performed at the Norwegian NMR Platform, RCN (226244/F50).

\section{References}

Arlov Ø, Aachmann FL, Feyzi E, Sundan A, SkjåkBræk G (2015) The impact of chain length and flexibility in the interaction between sulfated alginates and HGF and FGF-2. Biomacromolecules 16: 3417-3424. 
Arlov Ø, Aachmann FL, Sundan A, Espevik T, Skjåk-Bræk G (2014) Heparin-like properties of sulfated alginates with defined sequences and sulfation degrees. Biomacromolecules 15: 2744-2750.

Arlov Ø, Skjåk-Bræk G, Rokstad AM (2016) Sulfated alginate microspheres associate with factor $\mathrm{H}$ and dampen the inflammatory cytokine response. Acta Biomater 42: 180-188.

Berenbaum F (2013) Osteoarthritis as an inflammatory disease (osteoarthritis is not osteoarthrosis!). Osteoarthr Cartilage 21: 16-21.

Chen YL, Lee HP, Chan HY, Sung LY, Chen HC, Hu YC (2007) Composite chondroitin-6-sulfate/dermatan sulfate/chitosan scaffolds for cartilage tissue engineering. Biomaterials 28: 2294-2305.

Chia SL, Sawaji Y, Burleigh A, McLean C, Inglis J, Saklatvala J, Vincent T (2009) Fibroblast growth factor 2 is an intrinsic chondroprotective agent that suppresses ADAMTS-5 and delays cartilage degradation in murine osteoarthritis. Arthritis Rheum 60: 2019-2027.

Clutterbuck AL, Mobasheri A, Shakibaei M, Allaway D, Harris P (2009) Interleukin-1 beta-induced extracellular matrix degradation and glycosaminoglycan release is inhibited by curcumin in an explant model of cartilage inflammation. In Natural Compounds and Their Role in Apoptotic Cell Signaling Pathways 1171, Wiley-Blackwell pp 428-435.

Crofford LJ (1997) COX-1 and COX-2 tissue expression: implications and predictions. Journal of Rheumatology 24: 15-19.

Dalheim MO, Vanacker J, Najmi MA, Aachmann FL, Strand BL, Christensen BE (2015) Efficient functionalization of alginate biomaterials. Biomaterials 80: 146-156.

Darling EM, Athanasiou KA (2005) Rapid phenotypic changes in passaged articular chondrocyte subpopulations. J Orthop Res 23: 425-432.

David F, Farley J, Huang H, Lavoie JP, Laverty S (2007) Cytokine and chemokine gene expression of IL-1 beta stimulated equine articular chondrocytes. Vet Surg 36: 221-227.

Dyck SM, Karimi-Abdolrezaee S (2015) Chondroitin sulfate proteoglycans: Key modulators in the developing and pathologic central nervous system. Exp Neurol 269: 169-187.

Ertesvåg H (2015) Alginate-modifying enzymes: biological roles and biotechnological uses. Front Microbiol 6: 523 .

Freeman I, Kedem A, Cohen S (2008) The effect of sulfation of alginate hydrogels on the specific binding and controlled release of heparin-binding proteins. Biomaterials 29: 3260-3268.

Grant GT, Morris ER, Rees DA, Smith PJC, Thom D (1973) Biological interactions between polysaccharides and divalent cations - egg-box model. Febs Lett 32: 195198.

Hochart H, Jenkins PV, Smith OP, White B (2006) Low-molecular weight and unfractionated heparins induce a downregulation of inflammation: decreased levels of proinflammatory cytokines and nuclear factor-kappa B in
LPS-stimulated human monocytes. Brit J Haematol 133: 62-67.

Holtzer H, Abbott J, Lash J, Holtzer S (1960) The loss of phenotypic traits by differentiated cells in vitro.1. Dedifferentiation of cartilage cells. Proc Natl Acad Sci U S A 46: 1533-1542.

Johnson Z, Proudfoot AE, Handel TM (2005) Interaction of chemokines and glycosaminoglycans: a new twist in the regulation of chemokine function with opportunities for therapeutic intervention. Cytokine Growth F R 16: 625-636.

Jomphe C, Gabriac M, Hale TM, Heroux L, Trudeau LE, Deblois D, Montell E, Verges J, du Souich P (2008) Chondroitin sulfate inhibits the nuclear translocation of nuclear Factor-kappa B in interleukin-1 beta-stimulated chondrocytes. Basic Clin Pharmacol 102: 59-65.

Ke J, Long X, Liu Y, Zhang YF, Li J, Fang W, Meng QG (2007) Role of NF-kappa B in TNF-alpha-induced COX-2 expression in synovial fibroblasts from human TMJ. J Dent Res 86: 363-367.

Konttinen YT, Sillat T, Barreto G, Ainola M, Nordstrom DCE (2012) Osteoarthritis as an autoinflammatory disease caused by chondrocyte-mediated inflammatory responses. Arthritis Rheum 64: 613-616.

Legendre F, Bauge C, Roche R, Saurel AS, Pujol JP (2008) Chondroitin sulfate modulation of matrix and inflammatory gene expression in IL-1 beta-stimulated chondrocytes - study in hypoxic alginate bead cultures. Osteoarthr Cartilage 16: 105-114.

Lindahl U (2014) A personal voyage through the proteoglycan field. Matrix Biology 35: 3-7.

Lindahl U, Li JP (2009) Interactions between heparan sulfate and proteins-design and functional implications. Int Rev Cell Mol Bio 276: 105-159.

Linhardt RJ, Toida T (2004) Role of glycosaminoglycans in cellular communication. Accounts Chem Res 37: 431438.

Makris EA, Gomoll AH, Malizos KN, Hu JC, Athanasiou KA (2015) Repair and tissue engineering techniques for articular cartilage. Nat Rev Rheumatol 11: 21-34.

Martel-Pelletier J (1999) Pathophysiology of osteoarthritis. Osteoarthr Cartilage 7: 371-373.

Mengshol JA, Vincenti MP, Coon CI, Barchowsky A, Brinckerhoff CE (2000) Interleukin-1 induction of collagenase 3 (matrix metalloproteinase 13) gene expression in chondrocytes requires $\mathrm{p} 38$, c-Jun N-terminal kinase, and nuclear factor kappa B - Differential regulation of collagenase 1 and collagenase 3. Arthritis Rheum 43: 801-811.

Mhanna R, Kashyap A, Palazzolo G, Vallmajo-Martin Q, Becher J, Möller S, Schnabelrauch M, Zenobi-Wong M (2014) Chondrocyte culture in three dimensional alginate sulfate hydrogels promotes proliferation while maintaining expression of chondrogenic markers. Tissue Eng Part A 20: 1454-1464.

Miagkov AV, Kovalenko DV, Brown CE, Didsbury JR, Cogswell JP, Stimpson SA, Baldwin AS, Makarov SS (1998) NF-kappa B activation provides the potential link between inflammation and hyperplasia in the arthritic joint. Proc Natl Acad Sci U S A 95: 13859-13864. 
Mikami T, Kitagawa H (2013) Biosynthesis and function of chondroitin sulfate. Biochim Biophys Acta 1830: 4719-4733.

Mørch YA, Donati I, Strand BL, Skjåk-Bræk G (2006) Effect of $\mathrm{Ca}^{2+}, \mathrm{Ba}^{2+}$, and $\mathrm{Sr}^{2+}$ on alginate microbeads. Biomacromolecules 7: 1471-1480.

Mørch YA, Qi M, Gundersen POM, Formo K, Lacik I, Skjåk-Bræk G, Oberholzer J, Strand BL (2012) Binding and leakage of barium in alginate microbeads. J Biomed Mater Res A 100: 2939-2947.

Öztürk E, Arlov Ø, Aksel S, Li L, Ornitz DM, Skjåk-Bræk G, Zenobi-Wong M (2016) Sulfated hydrogel matrices direct mitogenicity and maintenance of chondrocyte phenotype through activation of FGF signaling. Adv Funct Mater 26: 3649-3662.

Parish CR (2006) The role of heparan sulphate in inflammation. Nat Rev Immunol 6: 633-643.

Pawar SN, Edgar KJ (2012) Alginate derivatization: A review of chemistry, properties and applications. Biomaterials 33: 3279-3305.

Pieper JS, van Wachem PB, van Luyn MJA, Brouwer LA, Hafmans T, Veerkamp JH, van Kuppevelt TH (2000) Attachment of glycosaminoglycans to collagenous matrices modulates the tissue response in rats. Biomaterials 21: 1689-1699.

Ramsden L, Rider CC (1992) Selective and differential binding of interleukin (Il)-1-alpha, Il-1-beta, Il-2 and Il-6 to glycosaminoglycans. Eur J Immunol 22: 3027-3031.

Rehm BHA, Valla S (1997) Bacterial alginates: biosynthesis and applications. Appl Microbiol Biotechnol 48: $281-288$.

Risbud MV, Sittinger M (2002) Tissue engineering: advances in in vitro cartilage generation. Trends Biotechnol 20: 351-356.

Rowley JA, Madlambayan G, Mooney DJ (1999) Alginate hydrogels as synthetic extracellular matrix materials. Biomaterials 20: 45-53.

Sandvig I, Karstensen K, Rokstad AM, Aachmann FL, Formo K, Sandvig A, Skjak-Braek G, Strand BL (2015)
RGD-peptide modified alginate by a chemoenzymatic strategy for tissue engineering applications. J Biomed Mater Res A 103: 896-906.

Shute J (2012) Glycosaminoglycan and chemokine/ growth factor interactions. Handb Exp Pharmacol 207: 307-324.

Spillmann D, Witt D, Lindahl U (1998) Defining the interleukin-8-binding domain of heparan sulfate. J Biol Chem 273: 15487-15493.

Spivak-Kroizman T, Lemmon MA, Dikic I, Ladbury JE, Pinchasi D, Huang J, Jaye M, Crumley G, Schlessinger J, Lax I (1994) Heparin-induced oligomerization of FGF molecules is responsible for FGF receptor dimerization, activation and cell-proliferation. Cell 79: 1015-1024.

Stokke BT, Smidsrød O, Bruheim P, Skjåk-Bræk G (1991) Distribution of uronate residues in alginate chains in relation to alginate gelling properties. Macromolecules 24: 4637-4645.

Stokke BT, Smidsrød O, Zanetti F, Strand W, SkjåkBræk G (1993) Distribution of uronate residues in alginate chains in relation to alginate gelling properties. 2. Enrichment of beta-D-mannuronic acid and depletion of alpha-L-guluronic acid in sol fraction. Carbohydrate Polymers 21: 39-46.

Vincenti MP, Brinckerhoff CE (2002) Transcriptional regulation of collagenase (MMP-1, MMP-13) genes in arthritis: integration of complex signaling pathways for the recruitment of gene-specific transcription factors. Arthritis Res 4: 157-164.

Weiler JM, Edens RE, Linhardt RJ, Kapelanski DP (1992) Heparin and modified heparin inhibit complement activation in vivo. J Immunol 148: 3210-3215.

There were no questions from reviewers, therefore there is no discussion with reviewers section for this paper.

Editor's note: The Scientific Editor responsible for this paper was Mauro Alini. 